\title{
Review Paper: The Study of Biomechanical Gait Cycle and Balance Characteristics in Intellectual Disabilities: A Systematic Review
}

\author{
Saeid Bahiraei $^{1^{*}}$ Q, Hassan Daneshmandi ${ }^{1}$ Q, Ali Asghar Norasteh ${ }^{1}$, Yahya Sokhangoei² 9 \\ 1. Department of Sport Injury and Corrective Exercises, School of Physical Education and Sport Sciences, University of Guilan, Rasht, Iran. \\ 2. Department of Rehabilitation Sciences, University of Social Welfare and Rehabilitation Sciences, Tehran, Iran.
}

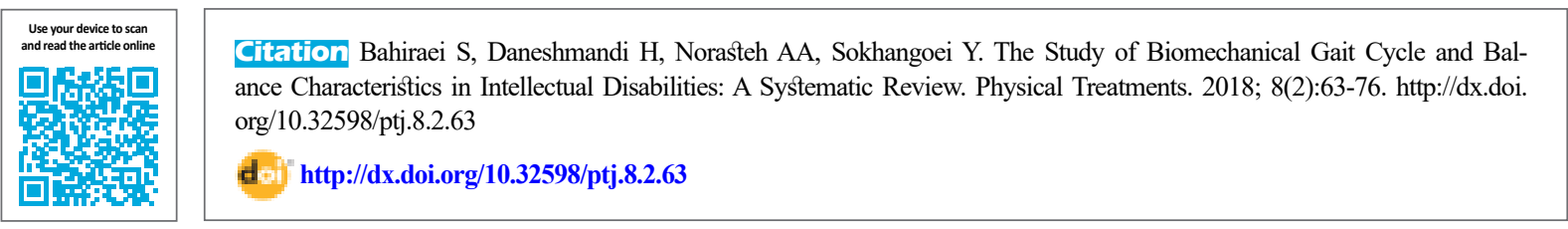

(a) $\mathrm{OQ}$

Article info:

Received: 10 Jan 2018

Accepted: 15 May 2018

Available Online: 01 Jul 2018

\begin{abstract}
A B S T RA C T
Purpose: Gait and balance are functionally related to motor performance. This study aimed to determine biomechanical features of gait in people with intellectual disabilities by reviewing articles published from 1992 to 2017.

Methods: In this systematic review, all quantitative studies related to gait and balance of people with intellectual disabilities were searched from Persian databases (Magiran, Irandoc, IranMedex, MedLib, SID, and Google Scholar) and all full text articles with keywords of "intellectual disability", "balance", "postural control", and "gait" were extracted from English databases (Science Direct, PubMed, EMBASE, Cochrane Review, TRIP, Pedro, CINAHL, ProQuest). Then, after complete review of articles, the English and Persian published papers on biomechanical parameters of gait cycle and balance in intellectual disabilities and related factors were extracted. Also, a "Data Extraction Form" which was developed based on research objectives, was used for data collection. Out of 56 related papers and research projects, 20 articles were excluded due to lack of meeting the inclusion criteria. Finally, 36 papers and research projects were included in this study.
\end{abstract}

Results: Of the 36 remained studies, the results showed that intellectual disabilities are usually accompanied with gait disorders, especially in step length, stride length, shorter step width, and lower velocity. It also has kinetic and kinematic disorders, including reduction of the ankle production power in the push-off phase, increased hip and knee flexion at stance phase, knee limitation and plantar ankle flexion at the heel contact, and joint stiffness during the gait cycle. The results showed that individuals with intellectual disabilities had significantly lower scores in the balance tests compared to their healthy peers.

Conclusion: Based on the results, the prevalence of gait disorders and balance in people with intellectual disability is high. Preventive measures should be taken in order to control gait disorders and balance. Therefore, it is suggested that occupational therapists, physiotherapists, sports experts, nurses, and other stakeholders try to find therapeutic strategies for preventing, control, and treatment of gait disorders. Also, because of the lack of intervention studies, future research must move from description to intervention studies in order to provide a guideline in clinical settings.
Intellectual disability,

Postural balance, Gait 


\section{Highlights}

- Gait characteristics influence health and future disability, falls, cognitive impairment, institutionalization, and mortality in the general population.

- People with Intellectual Disability (ID) have lower values for gait cycle time, swing in the gait cycle, step length, stride length, gait speed, and cadence than the general population.

- However, they have higher values for step width, stride width, the base of support, double support time, stance time, percent of stance and double support in the gait cycle.

- In general, people with ID show greater variability in their gait pattern than the general population.

- People with ID have lower values for balance than the general population.

\section{Plain Language Summary}

Balance and gait disorder are affected in people with Intellectual Disability (ID) compared to their age-matched peers in the general population. These problems start at a young age and remain during the entire life of people with ID. The relationship of these problems with falls has not yet been thoroughly investigated. As they are important risk factors for falls in the general older people, it can be expected that they are also important in people with ID. This needs to be confirmed in a large study with detailed screening of possible fall risk factors at baseline and then prospective monitoring. Furthermore, the finding that balance and gait are potentially trainable in people with ID suggests that falls might be prevented with ID-specific adjusted exercise interventions.

\section{Introduction}

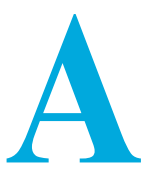

ccording to the American Association on Intellectual and Developmental Disabilities, Intellectual Disability (ID) refers to conditions where intellectual functioning is clearly less than the average level. ID also refers to concurrent limitations in adaptive behavior during the growth period before the age of 18. Its average worldwide prevalence range has been reported to be 1 to $3 \%$ [1]. Meanwhile, mild, moderate, severe, and profound IDs are observed in $85 \%, 10 \%$, $4 \%$, and $2 \%$ of the total population, respectively [2].

ID is associated with certain physio-anatomical features, distinguishing its sufferers from the normal population. For example, the ID patients' brain is lighter and smaller, they have decreased neuronal density, and owning to reduced neurotransmitters, they have synaptic dysfunction. Myelination abnormalities, reduced muscle tension, ligamentous laxity, vision and hearing impairments, inner ear neurosensory disorders, cardiovascular diseases, respiratory problems, etc., as well as appearance-related features, are other characteristics of ID [3-5].
Independent and secure participation in society and daily life activities is very important. Pathoneurological causes of motor impairment in patients with ID are unrecognized. However, cerebellar dysfunction, delayed myelination, vestibular disorders, proprioception, decreased muscle strength and tension, ligamentous laxity and visual impairments have been reported as the causes of this disorder [6]. Several mechanisms may cause balance and gait problems in ID patients. First, the incomplete development of mind which affects motor-cognitive function [7].

The second mechanism is premature aging. Balance and gait deterioration in these patients is related to aging because of decreased muscle strength and sensory function (vision, proprioception \& vestibular system). Age-related problems in ID patients are largely similar to the normal people. However, they occur more frequently and at younger ages in ID patients [8]. Additionally, given that life expectancy has increased, the number of older people with ID, as well as those with balance and gait problems is rapidly growing [9]. The third mechanism is lifestyle. ID patients are generally inactive [10]. As a result, their physical capacities such as endurance, balance, and strength are less than their healthy counterparts. 
Walking has been recognized as a cognitive function. Gait and balance refer to the integration of attention, planning, memory, and other motor, perceptual, and cognitive processes [11]. Gait and balance require efficiency, endurance, and spatiotemporal accuracy, which depending on gross motor skills, are acquired during the early stages of development. Any disruption in the development of these motor skills reduces individual autonomy and calls for constant support in daily activities [11].

Relative limitation in the joints, as well as weakness in the lower limb muscles, can disrupt such development process. Functional limitations of ID patients may be low. Thus, a correct walking pattern may be observed along with an impaired sensorimotor integration. This can cause reduced gait speed, larger cadence, a shorter stride and step length, larger step width, greater double leg support time, reduced lower limb joints mobility, biomechanical changes and adopting the strategy of "caution in taking steps", because of the fear of falling [12]. Considering motor impairments in these patients and the available reports on their gait and balance problems, this research aims to explore the biomechanical gait cycle and balance characteristics of ID patients.

\section{Materials and Methods}

This was a systematic review of studies published online from 1992 to 2017 . The keywords for the literature search used individually or together were "gait", "balance", and "intellectual disability". For detailed search, the following keywords were also used: "spatiotemporal gait parameters", "kinetics and kinematics of gait" ,"gait speed", "cadence”, "stride length", "step width", "static balance", "dynamic balance", "postural control and postural stability".

The online international databases for literature search were PubMed, EMBASE, Cochrane, TRIP, PEDro, MedLib, CINAHL, ProQuest, and Google Scholar. Additionally, the Iranian online databases included SID, Magiran, Irandoc, and IranMedex were searched too. At the initial screening stage, only the title and abstract of the candidate studies were considered for deciding on whether or not be included in the study in our review.

Inclusion criteria were studies on gait and balance of ID patients conducted during 1992-2017, published in English or Persian scientific research journals with full text available. Moreover, the exclusion criteria consisted of the lack of access to full texts, studying gait and balance of disabilities other than ID, and abstracts presented at conferences. A data extraction form was designed based on the research purpose. The selected studies were 56 , of which 20 were removed due to not meeting the inclusion criteria. Finally, 36 papers were reviewed. Of them, 16 were related to biomechanical gait cycle characteristics, and 20 were about the balance characteristics of ID patients. Figure 1 illustrates the process of selecting candidate studies for review.

\section{Results}

\section{Gait cycle characteristics of ID patients}

Table 1 presents the studies examining the biomechanical characteristics of the gait circle in ID patients during 1992-2017.

\section{Spatiotemporal parameters}

Most studies have examined spatiotemporal gait parameters of ID patients, including stride length, stride and step width, step length, velocity, cadence, Single Support Time (SST), Double Support Time (DST), and the base of support. In most studies, GAITRite system was used for spatiotemporal gait analysis, and treadmill to assess the walking speed. We applied a three-dimensional optoelectronic motion analysis system to measure spatiotemporal parameters.

The studies indicate that ID patients have a lower swing, step and stride length, speed, and cadence, compared to their normal peers. In contrast, Horvat et al. reported higher step and stride length in them [11]. Additionally, Smith et al. suggested a higher cadence in ID patients [13]. Most studies have reported higher step and stride width, the base of support, stance time percentage, stance time, DST percentage, and DST in ID patients. However, Gretz et al. [14] reported shorter step time and Horvat et al. [11] documented their lower scores in step width and DST.

Regarding other genetic syndromes, there were studies on patients with Prader-Willi Syndrome (PWS), reporting their higher scores in velocity and DST, and their lower scores in cadence, stride length and stance time as a percentage of gait cycle $[15,16]$. In one study, patients with Ehlers-Danlos syndrome were examined who had a longer stride, higher cadence, and shorter DST as a percentage of gait cycle [17].

For the ID people without syndromes, low gait speeds and step lengths have been reported in comparison with healthy counterparts. However, Sparrow et al. found higher gait speed and cadence, and shorter step and 
120 studies were found in the literature published from 1992 to 2017:

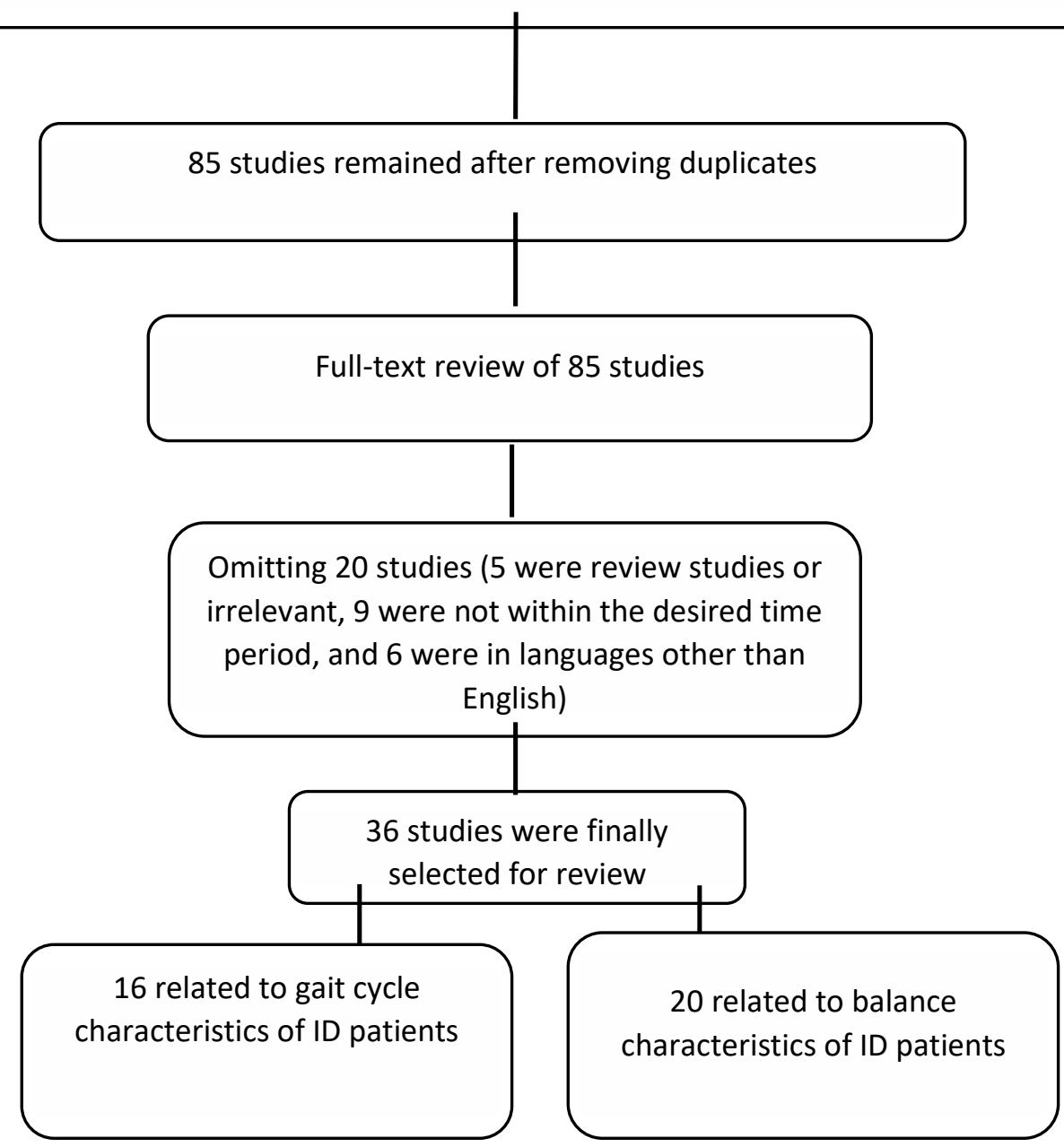

Figure 1. The screening process of studies selected for review

PHYSICAL TREA $\|$ MENTS

stride length in both male and female patients [18]. In general, it seems that ID patients walk faster and take longer strides in a shorter time. In addition, they have a lower base of support and shorter DST in a gait cycle, in comparison with ID patients with Down Syndrome (DS), indicating their better walking pattern.

\section{Kinematic characteristics}

Several studies have investigated the kinematic characteristics of gait in ID patients. These studies were carried out in motion analysis laboratories using motion analysis systems such as optoelectronic system, video recording, and GAITRite system with markers on anatomical landmarks. ID patients with DS demonstrated higher mean pelvic tilt and Range of Motion (ROM) of the pelvis on sagittal and frontal planes during the gait cycle compared to their typically developed peers $[16,17]$.

In hip joint, higher knee angle in the sagittal plane at the initial contact has been reported. Higher values for minimal hip flexion and maximum hip extension in stance phase and increased hip ROM on the frontal plane have also been reported for ID patients $[16,17$, $19,20]$. Another study reported lower ROM values of hip flexion-extension in the sagittal plane. The values of knee angle at the initial contact in the sagittal plane for DS patients were higher compared to their typically developed peers $[17,20]$. Studies reporting higher values 
of minimal knee flexion in the stance phase among DS patients were also available.

They have indicated the lower ROM values of knee flexion-extension and knee maximum flexion in swing phase $[16,17,19]$. For ankle joint kinematics in ID patients, the lower values of ankle angle in the sagittal plane at the initial contact and ROM of ankle dorsi-plantar flexion were also found [16, 17, 19, 20]. In addition, lower values for maximum ankle dorsiflexion at stance and swing phases as well as plantar flexion at the end of the stance phase were found. Kim et al. reported high external rotation in DS patients compared to their healthy peers [12].

In terms of the shoulder joint, Rigoldi et al. observed higher ROM in the frontal plane in a gait cycle in children, adolescents, and adults with DS [19]. Studies on people with DS suggested fast gait with higher cadence, shorter steps, higher double-support phase, and a wider stance in them. Rigoldi et al. observed gait quality and reduced cerebellar vermis volume in people with DS. They also reported an association between the prevalence of gait asymmetry and the reduction of gray matter volume [21].

In patients with PWS, higher values of pelvic tilt, hip flexion angle at the initial contact in the sagittal plane, minimal hip flexion in stance phase, and ROM of hip flexion-extension were documented $[15,16]$. In respect of the knee joint of PWS patients, higher values of knee angle at the initial contact in the sagittal plane were reported [16]. In addition, lower values of knee flexionextension ROM, minimal knee flexion in stance phase, and maximum knee flexion in swing phase were reported $[15,16]$.

For ankle joint of PWS patients, lower ankle angle at the initial contact in the sagittal plane was reported, as well as lower values for minimum and maximum ankle dorsiflexion in stance phase, and low ROM of ankle dorsi-plantar flexion. However, maximum ankle dorsiflexion at the swing phase was higher [16]. Haynes and Lockhart argued that ID adults had higher values of knee angle at the initial contact with the ground. However, they were not different from their healthy peers in terms of ankle angle at the initial contact [22].

\section{Kinetic characteristics}

Some studies were found on the kinetic characteristics of gait in ID patients. These studies only evaluated DS and PWS patients using treadmills or force plates. In comparison with healthy peers, higher first ankle peak force and lower second ankle peak force were reported in ID patients $[23,24]$.

Reduced ankle power generation and ground reaction force in mediolateral and anterior-posterior planes were observed in these patients, too $[12,17,19,20]$. In patients with PWS, Vismara et al. reported the low peak of plantar flexion moment and the low peak of ankle generated power [15]. Additionally, the peak of ankle power at the end of the stance phase was higher in these patients [16].

\section{Balance characteristics of ID patients}

Studies indicate that at steady state, the sway amplitude varies in subjects with ID, compared to the controls. People with ID also show a lateral oscillatory pattern, where increased sway in the anterior part of the frontal plane is higher than that in the sagittal plane. No significant correlation has been observed between sagittal/lateral sways and Intelligence Quotient (IQ) in ID subjects.

In a group of people with DS, sway amplitudes were not consistently greater than that of the control group, but they showed high rates of sway. Carmeli et al. indicated that the oscillation amplitude between eyes-closed and eyes-open resting conditions is higher in normal people compared to ID patients [31]. Most studies have demonstrated that individuals with ID have lower balance capacity and reduced ability to respond to external balance perturbations. According to Lahtinen et al. adolescents and adults with ID have impaired static balance, measured by the Stork balance test.

Carvalho and Almeida measured the longest time on a seesaw in persons with DS who were 21 years younger than the control counterparts (i.e. 28 VS. 49 years old). They found no difference between the groups [33]. Similarly, people with ID [34] and DS [6] showed decreased performance in the single leg stance test. Furthermore, individuals with ID [10] or DS [13] scored better in the Berg balance scale compared to their non-symptomatic peers. Posturography measures have suggested that patients with ID or DS have high sway amplitude and variability in comparison with controls. In addition, their balance strategy is based on shifting the body weight mediolaterally (Table 2).

Comparing individuals with ID, DS, and healthy peers revealed that ID patients have significantly more body sway than the DS and healthy individuals. Also, those with DS had significant differences with their healthy peers. Moreover, a significant correlation between the increased sway and the severity of disease was report- 
Table 1. Studies related to biomechanical characteristics of gait circle in ID patients without genetic syndromes

\begin{tabular}{|c|c|c|c|c|}
\hline Study & Subjects & $\begin{array}{c}\text { Number and Gender } \\
\text { of Subjects }\end{array}$ & $\begin{array}{l}\text { Assessment } \\
\text { Method }\end{array}$ & Main Findings \\
\hline 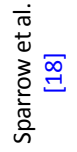 & $\begin{array}{l}\text { ID and non-ID subjects, } \\
\text { aged } 33-34 \text { years }\end{array}$ & $\begin{array}{l}16 \text { in each group (9 } \\
\text { females and } 7 \text { males) }\end{array}$ & $\begin{array}{l}\text { VHS Cam- } \\
\text { corder }\end{array}$ & $\begin{array}{l}\text { In both male and female subjects with ID, relative velocity, gait speed, } \\
\text { and cadence were higher than non-ID controls; however, they had } \\
\text { lower stride length and time. Moreover, no significant difference was } \\
\text { found between the two groups in the stance phase of the gait cycle. }\end{array}$ \\
\hline 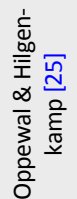 & $\begin{array}{l}\text { Patients with ID aged } \\
20-68 \text { years }\end{array}$ & $\begin{array}{l}15 \text { with mild ID and } \\
16 \text { with moderate ID, } \\
\text { including } 24 \text { males } \\
\text { and } 7 \text { females }\end{array}$ & GAITRite & $\begin{array}{l}\text { During dual tasking, participants walked slower, with a lower cadence, } \\
\text { increased stride time, and shorter stride lengths. They have spent less } \\
\text { time in the swing and single support phase than at comfortable speed. } \\
\text { However, dual tasking affects gait in patients with ID. This is an impor- } \\
\text { tant finding for safe community participation and must be considered } \\
\text { while interacting with ID patients during daily activities. }\end{array}$ \\
\hline
\end{tabular}

Participants with DS demonstrated how delay in cognitive aspects and the typical orthopedic features of DS, including ligament laxity would lead to the development of different motor strategies. During childhood, for both considered populations, large variability in the gait indexes was found, but after childhood, a split in gait develop-

Patients with DS, aged 9-38 years and healthy subjects, aged 8-37 years
32 with DS and $36 \quad 3 D$ Gait healthy subjects Analysis ment appeared. The study participants with DS developed a strategy focused on reducing the degrees of freedom, and increasing the dispersion of generated power in the frontal plane. However, in the healthy participants, the strategy was focused on the use of all degrees of freedom, to reach an efficient gesture and finalize their movements in sagittal progression. It was suggested that early interventions aiming to improve muscle tone, to supply excessive ligament laxity and improve motor coordination, could represent a real goal for a more effective movement

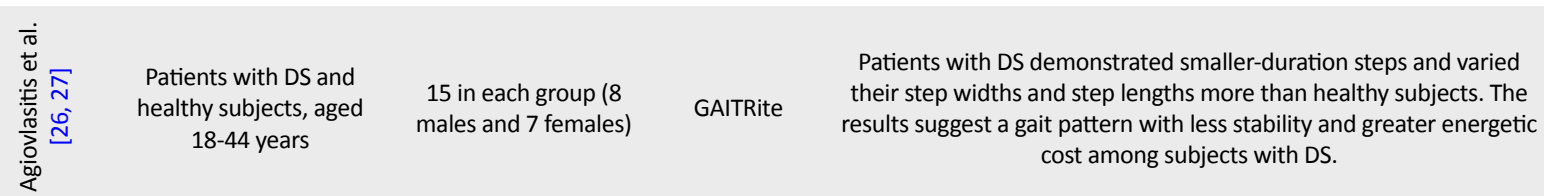

\begin{tabular}{|c|c|c|}
\hline 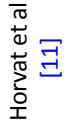 & $\begin{array}{c}\text { Patients with DS and } \\
\text { healthy subjects, aged } \\
18-28 \text { years }\end{array}$ & 12 in each group \\
\hline
\end{tabular}

Patients with DS, aged 25 years
9 (5 males, and 4 females)
DS patients demonstrated shorter step length, step width, stride length, and lower velocity, but higher stride width and longer single support time, compared to their healthy peers

\section{$\stackrel{\frac{\pi}{\pi}}{\frac{\pi}{0}}$ 澉守 \\ Patients with and with- out DS, aged 7-10 years \\ 10 in each group $(8$ males and 2 females) \\ Zebris \\ FDMT-S}

There were correlations between step length and stride length, between the shorter-duration step and the number of steps, between foot angle and the number of steps, and between gait cadence and the number of steps

The low peak of ankle power in terminal stance and before swing was observed in DS patients, which indicates low gait capacity during push off. Ankle load may, therefore, be included in the future physical interventions and exercise programs for the DS patients to strengthen their leg muscles and develop more efficient push off during locomotion in them.

Patients with and with- 15 in each group (11 3D Gait Analysis

ID group had significantly slower walking speed, shorter step lengths, and increased knee flexion angles at heel contact. These gait characteristics are known to reduce the odds of slip initiation in adults without ID. 


\begin{tabular}{|c|c|c|c|c|}
\hline Study & Subjects & $\begin{array}{c}\text { Number and Gender } \\
\text { of Subjects }\end{array}$ & $\begin{array}{l}\text { Assessment } \\
\text { Method }\end{array}$ & Main Findings \\
\hline 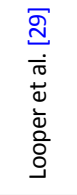 & $\begin{array}{c}\text { Patients with DS, aged } \\
4-7 \text { years }\end{array}$ & 6 & GAITRite & $\begin{array}{l}\text { Supramalleolar orthoses lead to a longer cycle time than foot ortho- } \\
\text { ses and barefoot walking, and a lower cadence than barefoot walking. } \\
\text { Significant strong correlations with gait parameters were obtained for } \\
\text { height, leg length, and hypermobility. The role of physical examina- } \\
\text { tion data, including anthropometric and biomechanical measure- } \\
\text { ments in the prescription of orthoses requires further investigation. }\end{array}$ \\
\hline 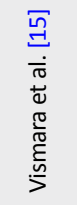 & $\begin{array}{l}\text { Patients with PWS, obesi- } \\
\text { ty, and healthy subjects }\end{array}$ & $\begin{array}{l}19 \text { with PWS ( } 11 \\
\text { males and } 8 \text { females), } \\
14 \text { with obesity ( } 5 \\
\text { males and } 9 \text { females, } \\
\text { and } 20 \text { healthy ( } 10 \\
\text { males and } 10 \text { females) }\end{array}$ & $\begin{array}{l}\text { Optoelec- } \\
\text { tronic system }\end{array}$ & $\begin{array}{l}\text { PWS patients walked slower, had a shorter stride length, a lower ca- } \\
\text { dence, and a longer stance phase, compared with both matched obese, } \\
\text { and healthy subjects. Obese patients showed significantly different } \\
\text { spatiotemporal parameters than the healthy subjects. Furthermore, } \\
\text { ROM at knee and ankle, and the plantar flexor activity of PWS patients } \\
\text { were significantly different between the obese and healthy subjects. }\end{array}$ \\
\hline 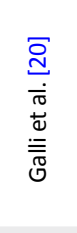 & $\begin{array}{c}\text { Patients with DS and } \\
\text { healthy subjects, aged } \\
11 \text { years }\end{array}$ & $\begin{array}{c}98 \text { with DS and } 30 \\
\text { healthy }\end{array}$ & $\begin{array}{l}\text { 3D Gait } \\
\text { analysis }\end{array}$ & $\begin{array}{l}\text { Subjects with DS walked with more hip flexion during the whole gait } \\
\text { cycle, knee flexion in stance phase, limitations in the knee range } \\
\text { of motion, and plantar flexion of the ankle at initial contact. Ankle } \\
\text { power was limited as evident in terminal stance and pre-swing, } \\
\text { represented by a low propulsive capacity at push-off, too. Hip joint } \\
\text { stiffness was increased in general in the patients with DS, versus } \\
\text { normal subjects; while ankle joint stiffness revealed a lower value. }\end{array}$ \\
\hline 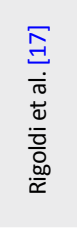 & $\begin{array}{c}\text { Patients with DS and } \\
\text { EDS, and healthy sub- } \\
\text { jects aged approximately } \\
40 \text { years }\end{array}$ & $\begin{array}{l}12 \text { with DS, } 16 \text { with } \\
\text { EDS, and } 20 \text { healthy }\end{array}$ & $\begin{array}{l}\text { 3D Gait } \\
\text { Analysis }\end{array}$ & $\begin{array}{l}\text { DS patients were characterized by a more compromised gait pattern } \\
\text { than EDS patients, even if both groups were characterized by joint } \\
\text { hypermobility. All the patients showed significantly decreased ankle } \\
\text { stiffness, probably due to congenital hypotonia and ligament laxity. } \\
\text { These findings help to elucidate the complex biomechanical changes } \\
\text { due to joint hypermobility and may play a major role in the multidi- } \\
\text { mensional evaluation and tailored management of these patients. }\end{array}$ \\
\hline
\end{tabular}

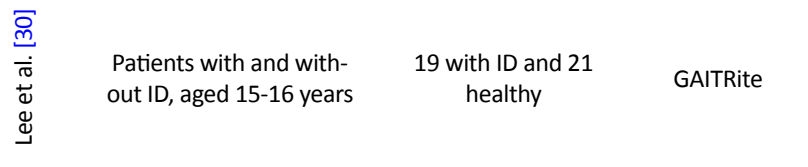

Patients with ID were significantly different from their healthy peers in terms of gait speed, cadence, step length, and stride length. Short stride length and wide stride width lead to increased cadence and instability.

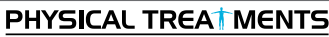

ed. However, a recent study argues that the severity of this disease has a negative effect on static and dynamic balance in children with ID. Thus, this characteristic remains controversial. Rigoldi et al. examined balance ability using posturography in three different age groups with and without DS, and found that they use different strategies, based on their age [19].

Children (aged 9-11 years) with DS had increased ROM of the Center of Pressure (COP) on the anteroposterior and mediolateral planes and increased trajectory length of the COP. Adolescents (aged 12-19 years) with DS had increased frequency in the anteroposterior and mediolateral deviation of the COP and increased ROM of the COP on the anteroposterior plane. Adults (aged 22-46 years) with DS showed high ROM of the COP on the anteroposterior and mediolateral planes and high frequency in the deviation of the COP on the anteroposterior axis [33].

There is no consensus among researchers regarding the importance of visual cues on balance, according to the degree of deterioration in eyes-closed balance. Many scholars have argued that people with ID and DS have higher body sway in eyes-closed condition, compared to the control groups. However, the findings of Dellavia et al. and Gomes and Barela $[35,36]$ are inconsistent with these results.

\section{Discussion}

Balance and gait characteristics of people with ID were reviewed in this paper. The results suggest that gait abnormalities and balance disorders in the ID population with and without genetic syndrome are evident. In comparison with healthy counterparts, ID people show more instability in balance and gait. In addition, they show an increased level of antagonistic co-contraction due to muscle stiffness during standing and walking. Walking in ID people is slower and asymmetrical with wider and shorter strides. The literature review reveals that most studies have explored spatiotemporal gait parameters, and less attention have been paid to kinematic characteristics. Only a few studies were found on the kinetic gait characteristics of ID patients which were conducted on DS and PWS groups. 
Table 2. The studies related to balance assessment in ID patients without genetic syndromes

\begin{tabular}{|c|c|c|c|c|}
\hline Study & Subjects & $\begin{array}{c}\text { Number and Gender } \\
\text { of Subjects }\end{array}$ & Assessment Method & Main Findings \\
\hline $\begin{array}{l}\text { Dellavia et } \\
\text { al. [35] }\end{array}$ & $\begin{array}{l}\text { Patients with and } \\
\text { without DS, aged } \\
20-39 \text { years }\end{array}$ & $\begin{array}{c}30 \text { with DS (15 males } \\
\text { and } 15 \text { females) } \\
\text { and } 30 \text { without DS } \\
\text { (15 males and } 15 \\
\text { females) }\end{array}$ & $\begin{array}{l}\text { Posturography and } \\
\text { Force Plate }\end{array}$ & $\begin{array}{l}\text { Patients with DS had larger sway of the center of foot pressure area } \\
\text { than the controls and smaller than the healthy subjects. All partici- } \\
\text { pants oscillated less with open eyes than with closed eyes. }\end{array}$ \\
\hline $\begin{array}{l}\text { Hale et al. } \\
\quad[37]\end{array}$ & $\begin{array}{l}\text { Patients with and } \\
\text { without ID, aged } \\
58 \text { years }\end{array}$ & $\begin{array}{l}7 \text { with ID ( } 4 \text { males } \\
\text { and } 3 \text { females), and } \\
13 \text { without ID (5 } \\
\text { males and } 8 \text { females) }\end{array}$ & Equitest & Adults with ID showed delayed responses to postural perturbations. \\
\hline $\begin{array}{l}\text { Blomqvist } \\
\text { et al. [38] }\end{array}$ & $\begin{array}{l}\text { Patients with and } \\
\text { without ID, aged } \\
16-20 \text { years }\end{array}$ & $\begin{array}{l}100 \text { with ID (60 } \\
\text { males and } 40 \\
\text { females), and } 155 \\
\text { without ID ( } 67 \text { males, } \\
\text { and } 88 \text { females) }\end{array}$ & $\begin{array}{l}\text { Timed up and go test, } \\
\text { single-leg stance, Dy- } \\
\text { namic one leg stance, } \\
\text { Functional reach test, } \\
\text { force platform test, } \\
\text { countermovement } \\
\text { jump, sit-ups, and } \\
\text { Biering-Sørensen } \\
\text { trunk extensor endur- } \\
\text { ance test }\end{array}$ & $\begin{array}{l}\text { In general, ID adolescents obtained significantly lower scores in tests, } \\
\text { compared to the other group. Visually dominated postural control, } \\
\text { height, BMI, and muscle performance were not strongly correlated } \\
\text { with balance performance in patients with and without ID. }\end{array}$ \\
\hline
\end{tabular}

$\begin{array}{cccc}\begin{array}{c}\text { Carvalho } \\ \text { and }\end{array} & \begin{array}{c}\text { Patients with and } \\ \text { without ID, aged }\end{array} & \begin{array}{c}\text { 6 in each group (3 } \\ \text { males and 3 females) }\end{array} & \text { 3D Gait analysis } \\ \begin{array}{c}\text { Almeida } \\ \text { [33] }\end{array} & 28 \text { years } & \end{array}$

Both groups maintained their balance mainly at the ankle joint. Contrary to the control group, those with DS, adopted a pattern of co-contraction and were unable to modulate the magnitude of postural response with the seesaw's degree of instability

\begin{tabular}{|c|c|c|c|c|}
\hline $\begin{array}{l}\text { Smith and } \\
\text { Ulrich [13] }\end{array}$ & $\begin{array}{l}\text { Patients with and } \\
\text { without DS }\end{array}$ & $\begin{array}{l}12 \text { with DS ( } 6 \text { males } \\
\text { and } 6 \text { females), } 12 \\
\text { without DS ( } 1 \text { male, } \\
\text { and } 11 \text { females) }\end{array}$ & Berg balance test & $\begin{array}{l}\text { Those with DS scores less in the Berg balance test compared to the } \\
\text { control group }\end{array}$ \\
\hline $\begin{array}{l}\text { Kokubun et } \\
\text { al. [39] }\end{array}$ & $\begin{array}{l}\text { Patients with DS } \\
\text { and ID, aged } 16 \\
\text { years }\end{array}$ & $\begin{array}{l}17 \text { with ID, and } 11 \\
\text { with DS }\end{array}$ & Force plate & $\begin{array}{l}\text { Higher frequencies of sway waves and lower single leg balance } \\
\text { were observed in patients with DS. The magnitudes of head sway } \\
\text { were not significantly different between the studied groups }\end{array}$ \\
\hline $\begin{array}{l}\text { Lahtinen et } \\
\text { al. [32] }\end{array}$ & $\begin{array}{l}\text { Patients with ID, } \\
\text { aged } 13 \text { years }\end{array}$ & $\begin{array}{c}77 \text { (33 females, } 44 \\
\text { males) }\end{array}$ & Single leg balance test & Low scores in single leg balance test were observed. \\
\hline $\begin{array}{l}\text { Gomes and } \\
\text { Barela [36] }\end{array}$ & $\begin{array}{l}\text { Patients with and } \\
\text { without DS, aged } \\
19-29\end{array}$ & $\begin{array}{l}9 \text { in each group ( } 4 \\
\text { males and } 4 \text { females) }\end{array}$ & Force plate & $\begin{array}{l}\text { Increased body sway in the DS group, compared to the control } \\
\text { group, and reduced body sway with eyes-closed, compared to } \\
\text { eyes-open conditions were observed. }\end{array}$ \\
\hline
\end{tabular}

$\begin{array}{cccc} & \text { Patients with } & & \\ \text { Hale et al. } & \begin{array}{c}\text { a profound ID } \\ \text { who experienced } \\ \text { a fall, aged } 52\end{array} & 20 \text { (14 males and } 6 & \text { females) } \\ \text { years } & & \text { Posturography }\end{array}$
Low scores in the Berg balance scale, functional reach, single leg stance, and walking on the balance beam, and increased scores in timed up and go test, and postural Responses were observed.

$\begin{array}{ccccc}\text { Galli et al. } \begin{array}{c}\text { Patients with and } \\ \text { without DS, aged } \\ 18 \text { years }\end{array} & \begin{array}{c}60 \text { with DS and } 10 \\ \text { healthy subjects }\end{array} & \begin{array}{c}\text { Patients with DS are characterized by unstable postural control. In } \\ \text { particular, the data evaluation in frequency domain indicated an } \\ \text { increase in frequency oscillation both in anteroposterior and me- } \\ \text { diolateral directions for DS subjects compared to the control group } \\ \text { that are confirmed in time domain analysis only for mediolateral } \\ \text { direction. In DS, no changes are evident between eyes open and } \\ \text { eyes closed condition. }\end{array}\end{array}$

$\begin{array}{cccc}\begin{array}{c}\text { Webber et } \\ \text { al. [41] }\end{array} & \begin{array}{c}\text { Patients with and } \\ \text { without DS, aged } \\ 30 \text { years }\end{array} & \begin{array}{c}9 \text { in each group }(3 \\ \text { males and } 6 \text { females })\end{array} & \text { Force Plate }\end{array}$

Increased amplitude and speed of sway and reduced postural stiffness were observed in the DS group. In addition, average stiffness measures were greater under the eyes-closed condition, than under the eyes-open condition for the DS group. 


\begin{tabular}{|c|c|c|c|c|}
\hline Study & Subjects & $\begin{array}{l}\text { Number and Gender } \\
\text { of Subjects }\end{array}$ & Assessment Method & Main Findings \\
\hline $\begin{array}{l}\text { Okuzumi et } \\
\text { al. [34] }\end{array}$ & $\begin{array}{l}\text { Adults with ID } \\
\text { aged } 19-22 \text { years } \\
\text { and non-handi- } \\
\text { capped children, } \\
\text { aged 3-6 years }\end{array}$ & 62 & $\begin{array}{l}\text { Two-dimensional } \\
\text { imaging }\end{array}$ & $\begin{array}{l}\text { Increased magnitude of head movement in children was evident } \\
\text { and the magnitude clearly was smaller at the age of } 6 \text { years. }\end{array}$ \\
\hline $\begin{array}{l}\text { Suomi and } \\
\text { Koceja [42] }\end{array}$ & $\begin{array}{l}\text { Patients with ID, } \\
\text { aged } 30 \text { years and } \\
\text { healthy subjects, } \\
\text { aged } 28 \text { years }\end{array}$ & $\begin{array}{l}22 \text { with ID and } 44 \\
\text { healthy subjects }\end{array}$ & Force plate & $\begin{array}{l}\text { Results indicated that the MR group exhibited significantly more } \\
\text { lateral sway than the other two groups, and that the sagittal/lateral } \\
\text { sway ratio was significantly lower in this group. Moreover, the MR } \\
\text { group showed a greater amount of sway in the no-vision condition } \\
\text { than either the M or W groups. Using the sagittal/lateral sway ratio, } \\
\text { the discriminant analyses indicated that group membership could } \\
\text { be predicted in } 75 \% \text { to } 82 \% \text { of the cases in the vision condition, and } \\
64 \% \text { to } 73 \% \text { of the cases in the no-vision condition. }\end{array}$ \\
\hline
\end{tabular}

\section{DePaepe \\ and}

Ciccaglione

[43]

$\begin{array}{cc}\text { ID patients, aged } & 91 \text { (67 males and } 24 \\ 35 \text { years } & \text { females) }\end{array}$

Papcsy-DePaepe Test and Bruininks-Oseretsky

test was observed, compared to those with profound ID. Furthermore, Bruininks-Oseretsky test scores in the ID patients had no associa-

tion with age and gender.

Analyses demonstrated that individuals with TD besides developmental disability had a different center of pressure orientation and variability compared to healthy individuals and individuals suffering only from developmental disability or TD. The center of pressure pattern in the developmentally disabled TD group was characterized by a more prominent lateral orientation, whereas in the other three groups, it had a more predominant anteroposterior orientation. In addition, the variability in these orientation components

was much smaller in the developmentally disabled TD group, indicating a more regular pattern of sway in the center of pressure during quiet standing in these individuals.

The findings showed that both tardive dyskinetic and/or developmentally disabled groups exhibited greater sway and variability in centre of pressure motion in contrast to the control group. The

Ko et al ID patients and

[45] healthy subjects, aged 36 years

with ID and 26

healthy subjects

Force plate developmentally disabled with tardive dyskinesia group also exhibited a strong tendency to produce a different form to the postural sway strategy so that they produced rhythmical centre of pressure motions during stance that were, to some extend, task dependent.

Increased ROM of the COP in mediolateral axis was observed in the children and adults with DS in contrast to the control group, while in anteroposterior axis, increased ROM of the COP was reported in the three groups. Reduced length of the COP trajectory in children with DS was also observed. Furthermore, they reported increased repetitive movements of DS patients in mediolateral and antero-
37 children, 58 adults
Force plate

$$
\text { posterior directions. }
$$

The result showed a significant difference between static and dynamic balance in two groups. Also, a significant relationship was observed between dynamic and static balance with IQ and age in girls with Down syndrome.

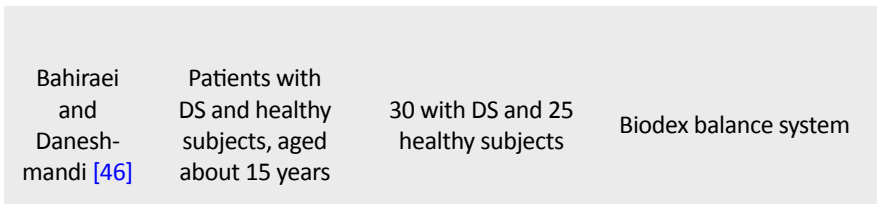

Pitetti et al. Patients with ID,

[47] aged 8-18 years
30 in each group Single Leg Balance test and Heel-to-Toe test

The results indicated that the forward head posture and balance of DS patients were significantly lower but the kyphosis angle of them was significantly higher than healthy participants. Moreover, a significant relationship was found between the forward head posture and anteroposterior balance test, and between the kyphosis with anteroposterior balance and finally between the kyphosis with general balance in individuals with Ds.

Mean scores for all age groups for balance, upper limb coordination, and bilateral coordination were consistently below BOT-2 criteria. Overall motor skills of males with ID are below the competence expected for children and adolescents without disabilities. 
Children and adults with DS demonstrate the general characteristics of walking with reduced stability, reflected by the displacement of the Center of Mass (COM). Specifically, reduced stability shown in adults with DS is documented by the increased variability in the base of stance width and step length by the increased mediolateral variability of the COM. It is also demonstrated by the higher mediolateral ROM of the COM, especially at higher gait speeds. Similar findings have been reported in studies on children with ID during the gait cycle [4]

The similarity of measures for assessing gait and balance characteristics in ID patients (such as posturography and gait analysis), allows the comparison of normal children. Thus, they can be used as a scale for examining growth retardation. Besides age, such similarities appear to be dependent on the IQ and frequency of motor skills experiences of these individuals [25].

ID groups are widely heterogeneous; therefore, there are various explanations for gait abnormalities which include their physio-cognitive specifications. Physical features, especially in ID people with genetic syndromes, have received more attention among researchers. For example, in those with DS, hypermobility has been reported to have a significant biomechanical effect on the gait pattern of these individuals due to ligamentous laxity and hypotonia which may explain the abnormalities of gait in DS people $[11,17,20]$.

In people with PWS, slower walking, shorter stride length, lower cadence, and longer stance phase have been observed. In addition, mediolateral variability of the COM may be because of severe obesity, low muscle strength, hypotonia and small feet [15]. All of these characteristics lead to a cautious walking pattern for maintaining stability during a gait cycle. However, gait abnormalities in individuals with ID, regardless of their syndrome and specific physical characteristics, cannot clearly explain all the disorders associated with these people. Therefore, the relationship between gait and the cognitive level is important. Such a relationship has been investigated in older adults with normal cognition and cognitive deficits. It was found that specific executive cognitive deficits would account for slower usual gait in aging [48].

Targeted cognitive interventions can improve gait performance [49]. For specific cognitive domains, it has been shown that the processing speed has been linked to temporal gait variables. This is while walking performance has been associated with spatial gait variables. Holtzer et al. reported that executive attention, memory, and verbal IQ are related to velocity. Gait abnormalities such as high gait variability and low velocity are related to cognitive decline, mild cognitive impairment and Alzheimer disease in the elderly [50].

One study evaluated the relationship between cognitive components with gait and balance in individuals with ID by performing dual tasking and walking over obstacles. Their obtained results indicated that, in the framework of walking and balance, it also has an additional cognitive challenge [51]. Under such conditions, it was revealed that participants increase their gait by stability adaptations, such as reducing velocity and increasing stride length and width. This cognitive component has received less attention in investigating the gait abnormalities in ID individuals.

In terms of falling associated with gait and balance, it can be argued that in addition to gait disturbance, it causes high energy costs [52]. It seems that mechanisms related to gait patterns such as hip joint extension, stride width, and cadence are related to energy cost in the elderly and gait variables [53]. In people with ID, gait variability leads to high oxygen uptake, increased heart rate, and a non-economic gait. Walking under perturbations and over obstacles adds additional stress to various cognitive abilities.

This forces the brain to perform another action before walking. Thus, changes in gait parameters (e.g. reducing velocity) can be a strategy before other actions. In the elderly, mild cognitive impairments and Alzheimer disease or dementia may worsen walking. Therefore, some disorders are correlated with certain cognitive domains such as dementia, cognitive impairment, and gait abnormalities which often coexist [50].

In ID people, age-related balance impairment is affected by the growth of motor reflex pathways, which regulate muscle tone and control posture. Studies reported that children with mild ID had lower scores compared to healthy children when performing single leg static balance test. Another factor that can affect balance is the increased variability in upper motor neurons. More specifically, increased variability in movement patterns can reflect higher neural responses in the postural control system to produce larger and faster corrections, especially during instability.

This adaptive process has also been observed in those with ID which can be due to either increased body sway velocity during posture or variations in muscle activation. According to the second hypothesis, a study indicates that ID had a significant effect on muscle activation patterns during the sit-to-stand task. In terms of dynamic 
balance, backward and forward movements on the base of support during standing on both feet, studies argue that individuals with ID have delayed reactive responses [37, 41]. This delay in reflex or premotor response may have implications in fall prevention. The delayed response can be related to lower physical activity associated with the inability to skillfully respond to balance perturbations.

This can induce anxiety and increase demands on cognitive attention. Increased co-contraction observed in people with ID under different circumstances causing stability and improving safety is another related mechanism. Aging in ID people in relation to their gait or balance characteristics is important. This is because in the elderly, aging is associated with impaired gait and balance [54]. Walking speed is an elderly person's health index. Walking and balance quality is strongly associated with falling in the adult population [55]. The prevalence of fall injuries in the mentally retarded population is $10.4 \%$. [56].

The balance and gait characteristics of people with ID are different compared to their healthy peers. These characteristics initiate at adolescence and are correlated with aging, which can cause serious problems. Despite the importance of falling in adults with ID, the association and mechanisms of these problems with falling are still unclear. It is important to highlight the role of training interventions in improving and reducing their problems.

\section{Ethical Considerations}

\section{Compliance with ethical guidelines}

This paper was approved by the Ethics Committee of Guilan University of Medical Sciences (Code: IR.GUMS.REC.1397.021).

\section{Funding}

This paper was extracted from a PhD. thesis of Saeid Bahiraei, Department of Sport Injury and Corrective Exercises, School of Physical Education and Sport Sciences, University of Guilan.

\section{Authors contributions}

Conceptualization: All authors; Methodology: Saeid Bahiraei and Hassan Daneshmandi; Investigation: All authors; Writing and original draft: Saeid Bahiraei; Writing, reviewing and editing: Hassan Daneshmandi and Ali Asghar Norasteh; Funding acquisition: All authors; Resources: All authors; and Supervision: Hassan Daneshmandi.

\section{Conflict of interest}

The authors declare no conflict of interest.

\section{References}

[1] Harris JC. Intellectual disability: Understanding its development, causes, classification, evaluation, and treatment. Oxford: Oxford University Press; 2006.

[2] Maulik PK, Mascarenhas MN, Mathers CD, Dua T, Saxena S. Prevalence of intellectual disability: A meta-analysis of population-based studies. Research in Developmental Disabilities. 2011; 32(2):419-36. [DOI:10.1016/j.ridd.2010.12.018] [PMID]

[3] Wu J, Ulrich DA, Looper J, Tiernan CW, Angulo Barroso RM. Strategy adoption and locomotor adjustment in obstacle clearance of newly walking toddlers with Down syndrome after different treadmill interventions. Experimental Brain Research. 2008; 186(2):261-72. [DOI:10.1007/s00221-0071230-7] [PMID]

[4] Rahmani P, Shahrokhi H. The study of static and dynamic balance in mentally retarded female students with and without Down Syndrome (DS). Journal of Sports Medicine. 2012; 2(2):97-113.

[5] Cabeza Ruiz R, García Massó X, Centeno Prada R, Beas Jiménez J, Colado J, González LM. Time and frequency analysis of the static balance in young adults with Down syndrome. Gait \& Posture. 2011; 33(1):23-8. [DOI:10.1016/j. gaitpost.2010.09.014] [PMID]

[6] Galli M, Rigoldi C, Mainardi L, Tenore N, Onorati P, Albertini G. Postural control in patients with Down syndrome. Disability and Rehabilitation. 2008; 30(17):1274-8. [DOI:10.1080/09638280701610353] [PMID]

[7] World Health Organization. nternational Classification of Functioning, Disability and Health (ICF). Geneva: World Health Organization; 2007.

[8] Evenhuis HM. Want ik wil nog lang leven: Moderne gezondheidszorg voor mensen met verstandelijke beperkingen: Zoetermeer: Raad voor de Volksgezondheid en Zorg; 2002.

[9] Janicki M, Dalton AJ, Michael Henderson C, Davidson PW. Mortality and morbidity among older adults with intellectual disability: Health services considerations. Disability and Rehabilitation. 1999; 21(5-6):284-94. [DOI:10.1080/096382899297710] [PMID]

[10] Hall JM, Thomas MJ. Promoting physical activity and exercise in older adults with developmental disabilities. Topics in Geriatric Rehabilitation. 2008; 24(1):64-73. [DOI:10.1097/01. TGR.0000311407.09178.55]

[11] Horvat M, Croce R, Zagrodnik J, Brooks B, Carter K. Spatial and temporal variability of movement parameters in individuals with down syndrome. Perceptual and Motor Skills. 2012; 114(3):774-82. [DOI:10.2466/25.15.26.PMS.114.3.774782] [PMID]

[12] Kim BS, Bang D, Kim BO. Gait characteristics in down's syndrome. Gait \& Posture. 1995; 3(2):84. [DOI:10.1016/09666362(95)93460-T] 
[13] Smith BA, Ulrich BD. Early onset of stabilizing strategies for gait and obstacles: Older adults with down syndrome. Gait \& Posture. 2008; 28(3):448-55. [DOI:10.1016/j.gaitpost.2008.02.002] [PMID] [PMCID]

[14] Gretz HR, Doering LL, Quinn J, Raftopoulos M, Nelson AJ, Zwick DE. Functional ambulation performance testing of adults with down syndrome. NeuroRehabilitation. 1998; 11(3):211-25. [DOI:10.1016/S1053-8135(98)00023-7]

[15] Vismara L, Romei M, Galli M, Montesano A, Baccalaro G, Crivellini M, et al. Clinical implications of gait analysis in the rehabilitation of adult patients with" Prader-Willi" syndrome: A cross-sectional comparative study (" Prader-Willi" syndrome vs matched obese patients and healthy subjects). Journal of NeuroEngineering and Rehabilitation. 2007; 4:14 [DOI:10.1186/1743-0003-4-14] [PMID] [PMCID]

[16] Cimolin V, Galli M, Grugni G, Vismara L, Albertini G, Rigoldi C, et al. Gait patterns in Prader-Willi and down syndrome patients. Journal of NeuroEngineering and Rehabilitation. 2010; 7:28. [DOI:10.1186/1743-0003-7-28] [PMID] [PMCID]

[17] Rigoldi C, Galli M, Cimolin V, Camerota F, Celletti C, Tenore N, et al. Gait strategy in patients with Ehlers-Danlos syndrome hypermobility type and Down syndrome. Research in Developmental Disabilities. 2012; 33(5):1437-42. [DOI:10.1016/j.ridd.2012.03.016] [PMID]

[18] Sparrow W, Shinkfield AJ, Summers J. Gait characteristics in individuals with mental retardation: Unobstructed levelwalking, negotiating obstacles, and stair climbing. Human Movement Science. 1998; 17(2):167-87. [DOI:10.1016/S01679457(97)00028-6]

[19] Rigoldi C, Galli M, Albertini G. Gait development during lifespan in subjects with down syndrome. Research in Developmental Disabilities. 2011; 32(1):158-63. [DOI:10.1016/j. ridd.2010.09.009] [PMID]

[20] Galli M, Rigoldi C, Brunner R, Virji Babul N, Giorgio A. Joint stiffness and gait pattern evaluation in children with Down syndrome. Gait \& Posture. 2008; 28(3):502-6. [DOI:10.1016/j. gaitpost.2008.03.001] [PMID]

[21] Rigoldi C, Galli M, Tenore N, Onorati P, Carducci F, Crivellini $\mathrm{M}$, et al. Relation between quantitative motion analysis and cerebral volumes analysis in down syndrome subjects. Gait \& Posture. 2008; 29(1):e31. [DOI:10.1016/j.gaitpost.2008.10.050]

[22] Haynes CA, Lockhart TE. Evaluation of gait and slip parameters for adults with intellectual disability. Journal of Biomechanics. 2012; 45(14):2337-41. [DOI:10.1016/j.jbiomech.2012.07.003] [PMID] [PMCID]

[23] Cioni M, Cocilovo A, Rossi F, Paci D, Valle MS. Analysis of ankle kinetics during walking in individuals with Down syndrome. American Journal of Mental Retardation. 2001 106(5):470-8. [DOI:10.1352/0895-8017(2001)1062.0.CO;2]

[24] Wu J, Ajisafe T. Kinetic patterns of treadmill walking in preadolescents with and without down syndrome. Gait \& Posture. 2014; 39(1):241-6. [DOI:10.1016/j.gaitpost.2013.07.113] [PMID]

[25] Oppewal A, Hilgenkamp TI. The dual task effect on gait in adults with intellectual disabilities: Is it predictive for falls? Disability and Rehabilitation. 2017:1-7. [DOI:10.1080/096382 88.2017.1370730] [PMID]
[26] Agiovlasitis S, McCubbin JA, Yun J, Mpitsos G, Pavol MJ Effects of down syndrome on three-dimensional motion during walking at different speeds. Gait \& Posture. 2009; 30(3):345-50. [DOI:10.1016/j.gaitpost.2009.06.003] [PMID]

[27] Agiovlasitis S, McCubbin JA, Yun J, Pavol MJ, Widrick JJ. Economy and preferred speed of walking in adults with and without Down syndrome. Adapted Physical Activity Quarterly. 2009; 26(2):118-30. [DOI:10.1123/apaq.26.2.118] [PMID]

[28] Lopes Pedralli M, Schelle GH. Gait evaluation in individuals with down syndrome. Brazilian Journal of Biomotricity. 2013; 7(1):20-7.

[29] Looper J, Benjamin D, Nolan M, Schumm L. What to measure when determining orthotic needs in children with Down syndrome: A pilot study. Pediatric Physical Therapy. 2012; 24(4):313-9. [DOI:10.1097/PEP.0b013e31826896eb] [PMID]

[30] Lee KJ, Lee MM, Shin DC, Shin SH, Song CH. The effects of a balance exercise program for enhancement of gait function on temporal and spatial gait parameters in young people with intellectual disabilities. Journal of Physical Therapy Science. 2014; 26(4):513-6. [DOI:10.1589/jpts.26.513] [PMID] [PMCID]

[31] Carmeli E, Kessel S, Bar Chad S, Merrick J. A comparison between older persons with down syndrome and a control group: clinical characteristics, functional status and sensorimotor function. Down's Syndrome, Research and Practice. 2004; 9(1):17-24. [PMID]

[32] Lahtinen U, Rintala P, Malin A. Physical performance of individuals with intellectual disability: A 30-year followup. Adapted Physical Activity Quarterly. 2007; 24(2):125-43. [DOI:10.1123/apaq.24.2.125] [PMID]

[33] Carvalho R, Almeida G. Assessment of postural adjustments in persons with intellectual disability during balance on the seesaw. Journal of Intellectual Disability Research. 2009; 53(4):389-95. [DOI:10.1111/j.1365-2788.2008.01147.x] [PMID]

[34] Okuzumi H, Tanaka A, Haishi K. Relationship between age and head movement during stepping in place by nonhandicapped children and persons with mental retardation. Perceptual and Motor Skills. 1997; 85(1):375-81. [DOI:10.2466/ pms.1997.85.1.375] [PMID]

[35] Dellavia C, Pallavera A, Orlando F, Sforza C. Postural stability of athletes in special olympics. Perceptual and Motor Skills 2009; 108(2):608-22. [DOI:10.2466/pms.108.2.608-622] [PMID]

[36] Gomes MM, Barela JA. Postural control in Down syndrome: The use of somatosensory and visual information to attenuate body sway. Motor Control. 2007; 11(3):224-34. [DOI:10.1123/mcj.11.3.224]

[37] Hale L, Miller R, Barach A, Skinner M, Gray A. Motor control test responses to balance perturbations in adults with an intellectual disability. Journal of Intellectual and Developmental Disability. 2009; 34(1):81-6. [DOI:10.1080/13668250802683810] [PMID]

[38] Blomqvist S, Olsson J, Wallin L, Wester A, Rehn B. Adolescents with intellectual disability have reduced postural balance and muscle performance in trunk and lower limbs compared to peers without intellectual disability. Research in Developmental Disabilities. 2013; 34(1):198-206. [DOI:10.1016/j.ridd.2012.07.008] [PMID] 
[39] Kokubun M, Shinmyo T, Ogita M, Morita K, Furuta M, Haishi K, et al. Comparison of postural control of children with down syndrome and those with other forms of mental retardation. Perceptual and Motor Skills. 1997; 84(2):499-504. [DOI:10.2466/pms.1997.84.2.499] [PMID]

[40] Hale L, Bray A, Littmann A. Assessing the balance capabilities of people with profound intellectual disabilities who have experienced a fall. Journal of Intellectual Disability Research. 2007; 51(4):260-8. [DOI:10.1111/j.13652788.2006.00873.x] [PMID]

[41] Webber A, Virji Babul N, Edwards R, Lesperance M. Stiffness and postural stability in adults with down syndrome. Experimental Brain Research. 2004; 155(4):450-8. [DOI:10.1007/s00221-003-1743-7] [PMID]

[42] Suomi R, Koceja DM. Postural sway patterns of normal men and women and men with mental retardation during a two-legged stance test. Archives of Physical Medicine and Rehabilitation. 1994; 75(2):205-9. [PMID]

[43] DePaepe JL, Ciccaglione S. A dynamic balance measure for persons with severe and profound mental retardation. Perceptual and Motor Skills. 1993; 76(2):619-27. [DOI:10.2466/ pms.1993.76.2.619] [PMID]

[44] Van Emmerik R, Sprague R, Newell K. Quantification of postural sway patterns in tardive dyskinesia. Movement Disorders. 1993; 8(3):305-14. [DOI:10.1002/mds.870080309] [PMID]

[45] Ko Y, Emmerik R, Sprague R, Newell K. Postural stability, tardive dyskinesia and developmental disability. Journal of Intellectual Disability Research. 1992; 36(4):309-23. [DOI:10.1111/j.1365-2788.1992.tb00530.x] [PMID]

[46] Bahiraei S, Daneshmandi H. [The study of relationship between structural profiles and postural control in individual with down syndrome (Persian)]. Journal of Practical Studies of Biosciences in Sports. 2014; 2(4):21-32.

[47] Pitetti K, Miller RA, Loovis M. Balance and coordination capacities of male children and adolescents with intellectual disability. Adapted Physical Activity Quarterly. 2017; 34(1):1-18. [DOI:10.1123/APAQ.2016-0010] [PMID]

[48] Watson N, Rosano C, Boudreau R, Simonsick E, Ferrucci L, Sutton-Tyrrell K, et al. Executive function, memory, and gait speed decline in well-functioning older adults. Journals of Gerontology Series A-Biological Sciences and Medical Sciences. 2010; 65(10):1093-100. [DOI:10.1093/gerona/glq111] [PMID] [PMCID]

[49] Montero-Odasso M, Verghese J, Beauchet O, Hausdorff JM. Gait and cognition: A complementary approach to understanding brain function and the risk of falling. Journal of the American Geriatrics Society. 2012; 60(11):2127-36. [DOI:10.1111/j.1532-5415.2012.04209.x] [PMID] [PMCID]

[50] Amboni M, Barone P, Hausdorff JM. Cognitive contributions to gait and falls: Evidence and implications. Movement Disorders. 2013; 28(11):1520-33. [DOI:10.1002/mds.25674] [PMID] [PMCID]

[51] Axer H, Axer M, Sauer H, Witte OW, Hagemann G. Falls and gait disorders in geriatric neurology. Clinical Neurology and Neurosurgery. 2010; 112(4):265-74. [DOI:10.1016/j. clineuro.2009.12.015] [PMID]

[52] Chambers HG, Sutherland DH. A practical guide to gait analysis. Journal of the American Academy of Orthopae- dic Surgeons. 2002; 10(3):222-31. [DOI:10.5435/00124635200205000-00009]

[53] Wert DM, Brach J, Perera S, VanSwearingen JM. Gait biomechanics, spatial and temporal characteristics, and the energy cost of walking in older adults with impaired mobility. Physical Therapy. 2010; 90(7):977-85. [DOI:10.2522/ ptj.20090316] [PMID] [PMCID]

[54] Verlinden VJ, van der Geest JN, Hofman A, Ikram MA. Cognition and gait show a distinct pattern of association in the general population. Alzheimer's \& Dementia. 2014; 10(3):328-35. [DOI:10.1016/j.jalz.2013.03.009] [PMID]

[55] Studenski S, Perera S, Patel K, Rosano C, Faulkner K, Inzitari M, et al. Gait speed and survival in older adults. JAMA. 2011; 305(1):50-8. [DOI:10.1001/jama.2010.1923] [PMID] [PMCID]

[56] Finlayson J, Morrison J, Jackson A, Mantry D, Cooper SA. Injuries, falls and accidents among adults with intellectual disabilities. Prospective cohort study. Journal of Intellectual Disability Research. 2010; 54(11):966-80. [DOI:10.1111/ j.1365-2788.2010.01319.x] [PMID] 
